\title{
Métodos de aplicação de fosfato na soja em plantio direto
}

\author{
Wagner Rogério Motomiya(1), Amoacy Carvalho Fabrício(2), Marlene Estevão Marchetti(1), \\ Manoel Carlos Gonçalves ${ }^{(1)}$, Antonio Dias Robaina ${ }^{(1)}$ e José Oscar Novelino ${ }^{(1)}$
}

\begin{abstract}
(1)Universidade Federal do Mato Grosso do Sul, Dep. de Ciências Agrárias, Caixa Postal 533, CEP 79804-970 Dourados, MS. E-mail:wagnerrm@uol.com.br, emarche@ceud.ufms.br, mancgonc@ceud.ufms.br, robaina@terra.com.br, jnovel@ceud.ufms.br (2)Embrapa Agropecuária Oeste, Caixa Postal 661, CEP 79804-970 Dourados, MS. E-mail: amoacy@cpao.embrapa.br
\end{abstract}

\begin{abstract}
Resumo - O objetivo deste trabalho foi avaliar o efeito de métodos de aplicação e fontes de adubo fosfatado no sistema plantio direto na produção de grãos de soja, num Latossolo Vermelho distroférrico argilo-arenoso. O delineamento experimental foi o de blocos casualizados, com parcelas subdivididas e quatro repetições. As parcelas constituíram-se dos modos de aplicação a lanço e em sulco de semeadura; as subparcelas foram representadas pela testemunha sem fósforo, por adubações de $120 \mathrm{~kg} \mathrm{ha}^{-1}$ e $80 \mathrm{~kg} \mathrm{ha}^{-1} \mathrm{de}_{2} \mathrm{O}_{5}$, no primeiro e segundo cultivo de soja, respectivamente, com superfosfato triplo (ST), fosfato de Gafsa (FG) e a combinação destas duas fontes $(67 \% \mathrm{ST}+33 \% \mathrm{FG}$ e $33 \% \mathrm{ST}+67 \% \mathrm{FG})$. As misturas de superfosfato triplo e de fosfato de Gafsa apresentam menor eficiência agronômica, quando comparadas ao superfosfato triplo. O fosfato de Gafsa, quando aplicado a lanço, é equivalente ao superfosfato triplo, no entanto, quando aplicado no sulco de semeadura, mostra-se ineficiente.
\end{abstract}

Termos para indexação: Glycine max, adubo fosfatado, fosfato natural, Latossolo.

\section{Phosphate application methods for soybean under no-tillage system}

\begin{abstract}
The objective of this research was to evaluate the effect of application methods and phosphate sources in the no-tillage system, on grain yield of soybean, in a Dark-Red Latosol clay-sandy. The experiment design was a complete randomized block with four replications. The treatments were arranged in split-plot. The plots were constituted of application methods (applied broadcast on the surface and in the band), and the subplots of the control with no phosphorus, of fertilization with $120 \mathrm{~kg} \mathrm{ha}^{-1}$ and $80 \mathrm{~kg} \mathrm{ha}^{-1}$ of $\mathrm{P}_{2} \mathrm{O}_{5}$, in the first and second soybean cultivation, respectively, with triple superphosphate (TS), Gafsa phosphate (GP) and the combination of these two sources $(67 \% \mathrm{TS}+33 \% \mathrm{GP}$ and $33 \% \mathrm{TS}+67 \% \mathrm{GP})$. The results showed that the mixtures of triple superphosphate and phosphate of Gafsa result in smaller agronomic efficiency, when compared to the triple superphosphate. The phosphate of Gafsa, when applied broadcast, is equivalent to the triple superphosphate, however, when applied in the band, it is inefficient for the soybean crop.
\end{abstract}

Index terms: Glycine max, phosphate fertilizer, rock phosphate, Latosol.

\section{Introdução}

A cultura de soja representa importante parcela na atividade agrícola brasileira, ocupando o segundo lugar entre os principais produtos, em área e valor de produção, com grande representatividade na pauta das exportações brasileiras (Melo Filho et al., 1996). Os solos em que a soja é cultivada normalmente apresentam alta capacidade de fixação de fósforo $(\mathrm{P})$ e isto, aliado à alta exigência dessa cultura por esse nutriente, torna o estabelecimento de formas e fontes de adubação fundamental.
Com a finalidade de melhorar a eficiência das adubações com P, Goedert \& Sousa (1986) definiram algumas estratégias, tais como minimização do poder de imobilização de $\mathrm{P}$ pelo solo, antes da aplicação do fosfato; determinação da melhor dose e do modo mais adequado de aplicação e incorporação; utilização de plantas mais eficientes na absorção e aproveitamento de P; desenvolvimento de tecnologia que permita aproveitar melhor as fontes de $\mathrm{P}$ disponíveis; maximização das interações positivas existentes entre adubação fosfatada e outras práticas agrícolas e combinação dos fatores de produção, visando obter a máxima produção por unidade de P aplicada ao solo. 
Praticamente toda a adubação fosfatada aplicada no sulco de semeadura é realizada com fontes solúveis em água. A utilização de fontes alternativas de custo mais baixo, como é o caso dos fosfatos reativos, aplicados com grande sucesso em pastagens, tem sido também eficiente em culturas anuais (Rajan et al., 1996). Esses fosfatos são rochas de origem sedimentar marinha e apresentam alto grau de substituições isomórficas, o que confere à partícula uma microestrutura porosa com elevada área superficial específica interna, advindo daí a sua reatividade com o solo (Chien \& Hammond, 1978).

Com o aumento do uso do sistema plantio direto, novas técnicas de aplicação para essas fontes necessitam ser avaliadas, já que a adoção desse sistema resulta em mudanças no ambiente edáfico.

A aplicação direta de fosfato natural é uma prática que vem sendo estudada como alternativa à aplicação de fosfatos solúveis no sulco de semeadura, comumente adotada. A eficiência dos fosfatos naturais reativos varia conforme a espécie cultivada em função da capacidade da planta em liberar prótons e assim acidificar sua rizosfera. Marschner (1991) encontrou valores de $\mathrm{pH}$ rizosférico até duas unidades inferiores ao solo nãorizosférico, em plantas nutridas com $\mathrm{N}$ amoniacal. Essa forte acidificação é observada principalmente em plantas leguminosas e outras espécies fixadoras de $\mathrm{N}$, de forma que estas espécies poderiam aumentar a dissolução de fosfatos naturais e, assim, serem utilizadas em rotação com outras que apresentam menor capacidade de acidificação (Gillespie \& Pope, 1990).

Segundo Chien \& Menon (1995), os fosfatos naturais são mais eficientes em leguminosas do que em cereais, e a eficiência relativa do fosfato natural é superior em vegetais com menor demanda de concentração de P na solução do solo, tais como as leguminosas, em relação aos cereais. Os ácidos orgânicos secretados por espécies de Rhizobium e Bradyrhizobium foram os principais fatores influenciadores da dissolução do fosfato de Mussorie, por meio da complexação do cálcio proveniente da rocha fosfática, enquanto o $\mathrm{pH}$ teve menor importância.

A aplicação de fosfatos naturais reativos em culturas anuais tem apresentado resultados equivalentes ao do superfosfato triplo, tanto em solos com teores iniciais médios de P (Choudhary et al., 1994), quanto naqueles com teores baixos (Braga et al., 1991; Fotyma et al., 1996).

O objetivo deste trabalho foi avaliar o efeito de métodos de aplicação e fontes de adubo fosfato no sistema plantio direto na produção de grãos de soja, num Latossolo Vermelho distroférrico argilo-arenoso.

\section{Material e Métodos}

O experimento foi realizado no campo da Embrapa Agropecuária Oeste, situado na latitude de $22^{\circ} 36^{\prime} \mathrm{S}$, longitude de $55^{\circ} 42^{\prime} \mathrm{W}$ e a $658 \mathrm{~m}$ de altitude, no Município de Ponta Porã, MS. O clima da região é do tipo Aw de acordo com a classificação de Köppen. A precipitação média anual é de $1.250 \mathrm{~mm}$ e as temperaturas média, máxima e mínima anuais são de $23^{\circ} \mathrm{C}, 26^{\circ} \mathrm{C}$ e $18^{\circ} \mathrm{C}$, respectivamente. As precipitações registradas no primeiro ano de condução da pesquisa foram mal distribuídas, observando-se períodos de estiagem nos meses de janeiro e fevereiro e primeiro decêndio de março, registrando-se 972,6 mm de precipitação pluviométrica entre novembro/1997 e março/1998. No segundo ano agrícola, não houve a ocorrência de estiagens, registrandose 1.202,4 mm de precipitação (Figura 1).

$\mathrm{O}$ solo da área experimental é classificado como Latossolo Vermelho distroférrico argilo-arenoso, com os seguintes atributos químicos, determinados segundo Embrapa (1997): $\mathrm{pH} \mathrm{em} \mathrm{CaCl}_{2} 0,01 \mathrm{~mol} \mathrm{~L}^{-1}, 5,1$; matéria orgânica, $27 \mathrm{~g} \mathrm{~kg}^{-1} ; \mathrm{P}, 4,3 \mathrm{mg} \mathrm{dm} \mathrm{dm}^{-3} ; \mathrm{V}, 56 \%$; e em $\mathrm{cmol}_{\mathrm{c}} \mathrm{dm}^{-3}$ : K, 0,13; Ca, 3,9; Mg, 1,2; $\mathrm{Al}, 0,1 ; \mathrm{H}+\mathrm{Al}$, 4,1; CTC, 9,33. A análise granulométrica apresentou $620 \mathrm{~g} \mathrm{~kg}^{-1}$ de areia, $80 \mathrm{~g} \mathrm{~kg}^{-1}$ de silte e $300 \mathrm{~g} \mathrm{~kg}^{-1}$ de argila. Os fatores estudados foram as fontes de $\mathrm{P}$, superfosfato triplo (ST), fosfato de Gafsa (FG) e duas misturas dos adubos, nas proporções de $67 \% \mathrm{ST}+$ $33 \%$ FG e $33 \%$ ST+67\% FG, aplicados a lanço, antes da semeadura e no sulco de semeadura; uma testemunha sem $\mathrm{P}$ foi utilizada, totalizando nove tratamentos.

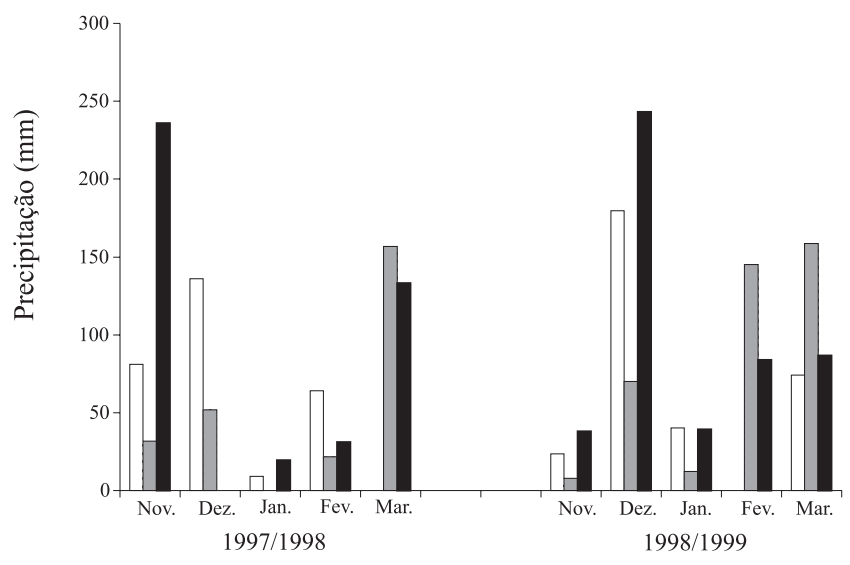

Figura 1. Precipitação pluvial (mm) registrada no primeiro ( $\square$ ), segundo ( $\square$ ) e terceiro ( $\square$ ) decêndios durante o cultivo da soja nas safras de 1997/1998 e 1998/1999. 
O delineamento experimental utilizado foi o de blocos casualizados, com quatro repetições. Os tratamentos foram dispostos num esquema de parcelas subdivididas, sendo as parcelas constituídas pelos modos de aplicação e as subparcelas pelas fontes de $\mathrm{P}$ e pela testemunha. A área total das subparcelas foi de $48 \mathrm{~m}^{2} \mathrm{e}$ o espaçamento entre linhas, nos dois anos, foi de $0,45 \mathrm{~m}$.

No cálculo da quantidade de cada adubo usado na formulação, foram utilizados os teores totais de $45 \%$ de $\mathrm{P}_{2} \mathrm{O}_{5}$ para o superfosfato triplo e $29 \%$ de $\mathrm{P}_{2} \mathrm{O}_{5}$ para o fosfato de Gafsa, cuja análise granulométrica apresentou os seguintes resultados: $\geq 20$ meshes: $2,37 \%$; 20-50 meshes: $28,41 \%$; $50-120$ meshes: $48,04 \%$ e $\geq 120$ meshes: $21,18 \%$. O superfosfato triplo foi moído com a finalidade de se obter maior homogeneidade da mistura dos adubos.

Foram avaliados dois cultivos consecutivos da cultura da soja, nos anos agrícolas 1997/1998 e 1998/1999, numa área cultivada anteriormente com a sucessão sojatrigo por dois anos, sob sistema de plantio direto.

A semeadura do primeiro cultivo foi efetuada em 29/11/1997, utilizando-se uma semeadora de parcela, que permitiu também a aplicação do adubo fosfatado em sulco, nos respectivos tratamentos. Independentemente da fonte e da forma de aplicação, a dose adotada foi de $120 \mathrm{~kg} \mathrm{ha}^{-1}$ de $\mathrm{P}_{2} \mathrm{O}_{5}$, de acordo com Kurihara \& Maeda (1996). A cultivar utilizada foi a BR-16. As sementes foram tratadas com Vitavax + Thiram $\left(300 \mathrm{~mL}^{-100 \mathrm{~kg}^{-1}}\right.$ de sementes) e inoculante turfoso (500 g $50 \mathrm{~kg}^{-1}$ de sementes). Na seqüência, procedeu-se à aplicação de $50 \mathrm{~kg} \mathrm{ha}^{-1}$ de FTE BR-12 (B, 1,8\%; Cu, 0,8\%; Fe, 3,0\%; $\mathrm{Mn}, 2,0 \%$; Mo, $0,1 \%$ e Zn, 9,8\%) e de $100 \mathrm{~kg} \mathrm{ha}^{-1}$ de $\mathrm{K}_{2} \mathrm{O}$, na forma de $\mathrm{KCl}$, em todas as parcelas, utilizando-se um distribuidor de calcário (Vincon). A adubação em cobertura foi realizada com $100 \mathrm{~kg} \mathrm{ha}^{-1} \mathrm{de} \mathrm{K}_{2} \mathrm{O}(\mathrm{KCl})$ e $30 \mathrm{~kg} \mathrm{ha}^{-1}$ de $\mathrm{N}$ (sulfato de amônio), a lanço aos 26 dias após a semeadura. Em 31/3/1998 procedeu-se à colheita de grãos.

O segundo cultivo foi realizado em 14/11/1998, utilizando-se a cultivar BR-64. Com o aumento nos teores de $\mathrm{P}$ no solo, por causa da adubação fosfatada do cultivo anterior, aplicaram-se $80 \mathrm{~kg} \mathrm{ha}^{-1} \mathrm{de}_{2} \mathrm{O}_{5}$, dos respectivos tratamentos, seguido da aplicação a lanço de $100 \mathrm{~kg} \mathrm{ha}^{-1} \mathrm{de}_{2} \mathrm{O}$, na forma de $\mathrm{KCl}$. As sementes foram tratadas como no primeiro cultivo. Aos 26 dias após a semeadura, realizou-se a adubação em cobertura, como no primeiro cultivo. A colheita foi realizada em 19/3/1999.

A amostragem de tecido foliar foi feita no estádio de florescimento pleno, coletando-se o terceiro trifólio com pecíolo, compondo-se uma amostra com 20 folhas por subparcela, para avaliação dos teores de fósforo. As folhas foram, inicialmente, lavadas com água destilada, secadas em estufa com circulação forçada de ar a $65^{\circ} \mathrm{C}$

$\mathrm{Na}$ avaliação dos teores de $\mathrm{P}$ nos grãos, seguiu-se o mesmo procedimento para a secagem dos grãos. As folhas e os grãos foram moídos, separadamente, em moinho tipo Willey, provido de peneira de aço inoxidável, com 20 malhas por polegada. O P foi extraído dos materiais por meio de digestão nítrico-perclórica e determinado pelo método colorimétrico do metavanadato (Malavolta et al., 1997).

Em cada subparcela, após a colheita da soja, abriram-se trincheiras nas quais foram coletadas amostras de solo nas camadas de $0-0,025,0,025-0,05$, $0,05-0,10$ e $0,10-0,20 \mathrm{~m}$, em forma de fatias, com $0,45 \mathrm{~m}$ (espaçamento de semeadura da soja) de comprimento, $0,03 \mathrm{~m}$ de espessura e largura correspondente às diversas camadas. As amostras foram secadas ao ar livre e todo o material coletado foi homogeneizado para a determinação do teor de $\mathrm{P}$ pelo método da resina trocadora de íons, segundo Raij et al. (1986).

No ano agrícola 1998/1999, calculou-se o índice de eficiência agronômica segundo a fórmula:

IEA $=100 \times$ (Produção de grãos no tratamento - Produção de grãos na testemunha) $\div$ (Produção de grãos no supertriplo - Produção de grãos na testemunha).

Foram realizadas análises de variância e de correlação, para as características avaliadas, comparando-se as médias pelo teste de Tukey a $5 \%$ de probabilidade, para os teores de $\mathrm{P}$ no solo e a 10\% de probabilidade para as demais características avaliadas.

\section{Resultados e Discussão}

No primeiro ano, quando o adubo fosfatado foi aplicado a lanço, obteve-se nas camadas de $0-0,025 \mathrm{~m} \mathrm{e}$ $0,025-0,05 \mathrm{~m}$ teores de $\mathrm{P}$ significativamente superiores ao da testemunha, o que demonstra ter havido aumento na sua disponibilidade com este método de aplicação até $0,05 \mathrm{~m}$ de profundidade. Beck \& Sanchez (1996), em solos com textura semelhante ao utilizado no presente trabalho, também observaram aumento significativo no teor de $\mathrm{P}$ abaixo da camada em que o nutriente foi aplicado. Não houve diferença significativa no teor de $\mathrm{P}$ entre as fontes avaliadas, nas camadas de 0,05-0,10 m e 0,10-0,20 m (Figura 2). Na aplicação no sulco de semeadura, as médias apenas na camada $0,05-0,10 \mathrm{~m}$ foram significativamente diferentes da 
testemunha. Nessa camada, a aplicação de fosfato de Gafsa puro proporcionou a maior disponibilidade de $\mathrm{P}\left(130,2 \mathrm{mg} \mathrm{dm}^{-3}\right)$.

$\mathrm{Na}$ análise de solo realizada em 1999, a aplicação a lanço resultou em diferença significativa entre a testemunha e os tratamentos com fósforo, apenas na primeira camada de solo analisada; nas outras camadas, observaram-se valores semelhantes, obtendo-se teores mais elevados nos tratamentos com fósforo (Figura 3). Com relação à aplicação no sulco de semeadura, constatou-se maior teor de $\mathrm{P}$ disponível no tratamento com a forma menos solúvel, na profundidade $0,05-0,10 \mathrm{~cm}$, fato também observado no ano anterior. Isto se explica pelo fato de que, no sulco de semeadura, a dissolução é menor, por causa do restrito volume de solo em contato com o fertilizante e, conseqüientemente, menores quantidades de P são absorvidas pela planta (Novais \& Smyth, 1999). A aplicação de P no sulco de semeadura, na profundidade de $0,10-0,20 \mathrm{~m}$, resultou em teores significativamente maiores de $\mathrm{P}$, em relação à testemunha, nas formulações que continham maior quantidade da fonte solúvel.

A comparação dos teores de $\mathrm{P}$, em função das fontes de $\mathrm{P}$, nos dois anos de amostragem, permitiu verificar que houve redução da disponibilidade desse nutriente, principalmente quando a aplicação foi a lanço, não obstante tenha-se aplicado mais $80 \mathrm{~kg} \mathrm{ha}^{-1}$ no ano agríco-
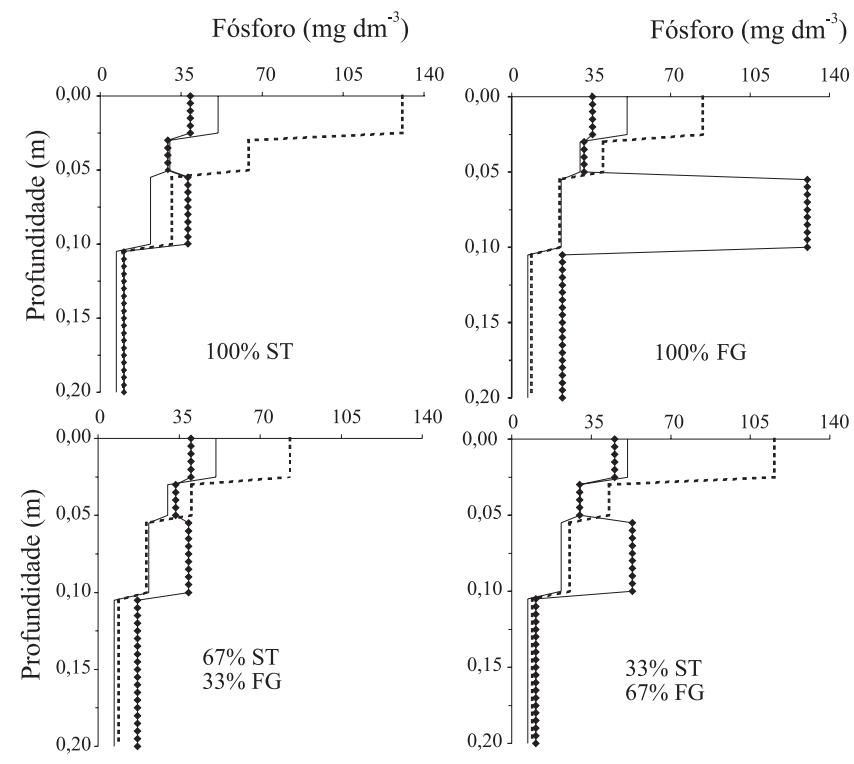

Figura 2. Teores de fósforo no solo, obtidos pelo método da resina, nas diversas profundidades amostradas, em razão das fontes de fósforo superfosfato triplo (ST) e fosfato de Gafsa (FG) e dos métodos de aplicação: testemunha (-), sulco (-) e a lanço (----), em 1998. la 1998/1999. Além da extração pelas plantas de soja, a fixação do $\mathrm{P}$ pode ter influenciado nessa redução.

$\mathrm{O}$ desenvolvimento e a produtividade da cultura da soja (Tabela 1) foram muito prejudicados por causa da estiagem ocorrida entre a segunda quinzena de dezembro de 1997 e o final de janeiro de 1998 e das baixas precipitações até o mês de março (Figura 1). Por isso não foi possível discutir a viabilidade de aplicação de fosfato de Gafsa no primeiro ano de aplicação.

Em trabalhos semelhantes, realizados em solos com baixo teor inicial de $\mathrm{P}$, também têm sido obtidas baixas produtividades no primeiro ano de aplicação de fosfatos naturais, seguidos de aumentos na produtividade de grãos, nos anos posteriores (Goedert \& Lobato, 1984). Contudo, existem trabalhos mostrando que a aplicação de fosfatos naturais reativos é uma alternativa viável já no primeiro ano de aplicação (Braga et al., 1991; Fotyma et al., 1996).

Os teores de $\mathrm{P}$ na folha, nos tratamentos com fosfato de Gafsa puro aplicado no sulco, foram semelhantes aos da testemunha, mas significativamente inferiores ao do superfosfato triplo puro, em ambos os métodos de aplicação (Tabela 1). Nos grãos obtiveram-se menor teor de P, com a utilização de fosfato de Gafsa puro aplicado no sulco.

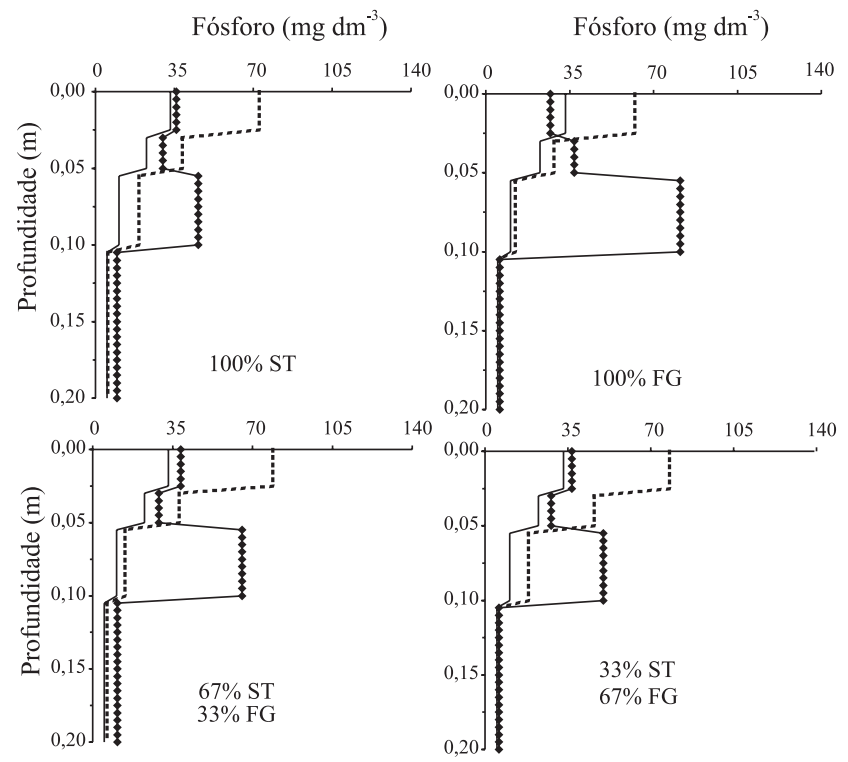

Figura 3. Teores de fósforo no solo, obtidos pelo método da resina, nas diversas profundidades amostradas, em razão das fontes de fósforo superfosfato triplo (ST) e fosfato de Gafsa (FG) e dos métodos de aplicação: testemunha $(\rightarrow)$, sulco $(\rightarrow)$ e a lanço (----), em 1999. 
Na safra 1997/1998, ocorreram períodos de seca entre a segunda quinzena de dezembro e final de fevereiro (Figura 1) e, por isso, as produtividades foram prejudicadas e não se obtiveram correlações significativas entre as características analisadas (Tabela 2).

No ano agrícola 1998/1999 na aplicação do P a lanço, os tratamentos com P não apresentaram diferenças significativas e as produtividades médias obtidas foram superiores à da testemunha (Tabela 1).

$\mathrm{Na}$ aplicação do $\mathrm{P}$ no sulco de semeadura, as produtividades foram maiores nos tratamentos que receberam maior quantidade de superfosfato triplo. Com relação aos métodos de aplicação, houve diferença significativa, sendo que o superfosfato triplo + fosfato de Gafsa, na proporção de $33 \%+67 \%$, e o fosfato de Gafsa

Tabela 1. Produtividade de grãos de soja e teores de fósforo na folha e nos grãos, em razão dos tratamentos com superfosfato triplo (ST) e fosfato de Gafsa (FG), obtidos em 1997/1998 e em 1998/1999(1).

\begin{tabular}{lllll}
\hline Fonte & \multicolumn{3}{c}{$1997 / 1998$} & \multicolumn{2}{c}{$1998 / 1999$} \\
\cline { 2 - 4 } \cline { 4 - 5 } & Lanço & Sulco & Lanço & Sulco \\
\hline Testemunha & $1.511 \mathrm{abA}$ & $1.511 \mathrm{aA}$ & $2.220 \mathrm{cA}$ & $2.220 \mathrm{bA}$ \\
$100 \% \mathrm{ST}$ & $1.538 \mathrm{abA}$ & $1.465 \mathrm{aA}$ & $2.566 \mathrm{aA}$ & $2.553 \mathrm{aA}$ \\
$67 \% \mathrm{ST}+33 \% \mathrm{FG}$ & $1.479 \mathrm{bA}$ & $1.526 \mathrm{aA}$ & $2.489 \mathrm{abcA}$ & $2.390 \mathrm{abA}$ \\
$33 \% \mathrm{ST}+67 \% \mathrm{FG}$ & $1.631 \mathrm{aA}$ & $1.436 \mathrm{aB}$ & $2.503 \mathrm{abcA}$ & $2.280 \mathrm{abB}$ \\
$100 \% \mathrm{FG}$ & $1.505 \mathrm{abA}$ & $1.397 \mathrm{aA}$ & $2.546 \mathrm{abA}$ & $2.229 \mathrm{bB}$ \\
\hline \multicolumn{5}{c}{ Fósforo na folha $\left(\mathrm{g} \mathrm{kg}^{-1}\right)$} \\
Testemunha & $1,42 \mathrm{abA}$ & $1,42 \mathrm{bA}$ & $0,85 \mathrm{aA}$ & $0,85 \mathrm{bA}$ \\
$100 \% \mathrm{ST}$ & $1,68 \mathrm{aB}$ & $2,01 \mathrm{aA}$ & $1,10 \mathrm{aB}$ & $2,15 \mathrm{aA}$ \\
$67 \% \mathrm{ST}+33 \% \mathrm{FG}$ & $1,48 \mathrm{abA}$ & $1,75 \mathrm{aA}$ & $1,37 \mathrm{aB}$ & $2,08 \mathrm{aA}$ \\
$33 \% \mathrm{ST}+67 \% \mathrm{FG}$ & $1,56 \mathrm{abA}$ & $1,36 \mathrm{bA}$ & $1,00 \mathrm{aB}$ & $2,02 \mathrm{aA}$ \\
$100 \% \mathrm{FG}$ & $1,34 \mathrm{bA}$ & $1,43 \mathrm{bA}$ & $0,90 \mathrm{aB}$ & $1,99 \mathrm{aA}$ \\
\hline \multicolumn{5}{c}{ Fósforo nos grãos $\left(\mathrm{g} \mathrm{kg}{ }^{-1}\right)$} \\
Testemunha & $4,99 \mathrm{aA}$ & $4,99 \mathrm{cA}$ & $3,95 \mathrm{aA}$ & $3,95 \mathrm{abA}$ \\
$100 \% \mathrm{ST}$ & $5,64 \mathrm{aA}$ & $5,90 \mathrm{abA}$ & $4,45 \mathrm{aA}$ & $4,78 \mathrm{aA}$ \\
$67 \% \mathrm{ST}+33 \% \mathrm{FG}$ & $5,61 \mathrm{aA}$ & $6,06 \mathrm{aA}$ & $4,23 \mathrm{aA}$ & $4,37 \mathrm{abA}$ \\
$33 \% \mathrm{ST}+67 \% \mathrm{FG}$ & $5,78 \mathrm{aA}$ & $5,69 \mathrm{abcA}$ & $3,90 \mathrm{aA}$ & $3,93 \mathrm{abA}$ \\
$100 \% \mathrm{FG}$ & $5,38 \mathrm{aA}$ & $5,10 \mathrm{bcA}$ & $3,91 \mathrm{aA}$ & $3,82 \mathrm{bA}$ \\
\hline
\end{tabular}

${ }^{(1)}$ Médias seguidas pela mesma letra, minúscula na coluna e maiúscula na linha, não diferem entre si pelo teste de Tukey a $10 \%$ de probabilidade.

Tabela 2. Coeficientes de correlação e níveis de significância em relação aos teores de fósforo na planta e em várias profundidades no solo, em razão das produtividades de soja e trigo, obtidos em 1998 e 1999.

\begin{tabular}{|c|c|c|c|c|}
\hline \multirow[t]{2}{*}{ Teores de fósforo } & \multicolumn{2}{|c|}{ Lanço } & \multicolumn{2}{|c|}{ Sulco } \\
\hline & 1998 & 1999 & 1998 & 1999 \\
\hline Folha & $0,459^{\text {ns }}$ & $0,412^{\mathrm{ns}}$ & $0,329^{\mathrm{ns}}$ & $0,554^{\mathrm{ns}}$ \\
\hline Grãos & $0,506^{\mathrm{ns}}$ & $0,381^{\mathrm{ns}}$ & $0,314^{\mathrm{ns}}$ & $0,982^{*}$ \\
\hline $0,000-0,025 \mathrm{~m}$ & $0,564^{\mathrm{ns}}$ & $0,859 *$ & $0,497^{\mathrm{ns}}$ & $0,541^{\mathrm{ns}}$ \\
\hline $0,025-0,050 \mathrm{~m}$ & $0,201^{\mathrm{ns}}$ & $0,643^{\mathrm{ns}}$ & $0,224^{\mathrm{ns}}$ & $0,040^{\mathrm{ns}}$ \\
\hline $0,050-0,100 \mathrm{~m}$ & $0,488^{\text {ns }}$ & $0,673^{\text {ns }}$ & $-0,834^{\text {ns }}$ & $0,077^{\mathrm{ns}}$ \\
\hline $0,100-0,200 \mathrm{~m}$ & $0,242^{\text {ns }}$ & $0,399^{\text {ns }}$ & $-0,457^{\text {ns }}$ & $0,819 *$ \\
\hline
\end{tabular}

ns Não-significativo. *Significativo a $5 \%$ de probabilidade, pelo teste $\mathrm{F}$. puro resultaram em produtividades inferiores, quando aplicados no sulco de semeadura. Isso é explicado pelo menor contato do fosfato de Gafsa com o solo, resultando em menor dissolução e, conseqüentemente, menor disponibilidade para a planta, pois a quantidade de $\mathrm{P}$ disponível à planta fica restrita à parte solúvel aplicada na mistura. Nesses tratamentos, a melhor alternativa foi a aplicação a lanço.

Os teores de $\mathrm{P}$ nas folhas, nos tratamentos a lanço, foram significativamente inferiores aos decorrentes da aplicação no sulco de semeadura (Tabela 1). Pelos baixos teores de P na folha (Tabela 1), infere-se que a produtividade obtida na cultura da soja superou as expectativas. Braga et al. (1991) observaram que foram necessárias doses elevadas de fosfato natural reativo para atingir a faixa de suficiência, que está entre 2,6 e $5,0 \mathrm{~g} \mathrm{~kg}^{-1}$.

Com relação aos teores de $\mathrm{P}$ nos grãos, não houve diferença nos tratamentos com o fosfato aplicado a lanço; todavia, quando a aplicação foi realizada no sulco de semeadura, observou-se diferença significativa entre os fosfatos aplicados, com evidentes acréscimos nos teores de $\mathrm{P}$ nos tratamentos que receberam maior quantidade de superfosfato triplo.

Correlações positivas entre os teores de $\mathrm{P}$ no solo e as produtividades de soja também foram obtidas. Quando o P foi aplicado a lanço, houve correlações significativas entre a produtividade de grãos e os teores de $\mathrm{P}$ obtidos na camada de $0-0,025 \mathrm{~m}$, e quando a aplicação foi realizada no sulco, houve correlação significativa na camada de 0,100-0,200 m, no ano de 1999.

A explicação para os bons resultados obtidos com a aplicação de fosfato de Gafsa na superfície do solo se deve ao fato de que apesar de proporcionar menor contato do fosfato reativo com as frações do solo, se comparado à sua incorporação, esse contato é maior do que o obtido com sua aplicação no sulco de semeadura (Rajan et al., 1996). Além disso, existem condições para sua maior dissolução, proporcionadas pelo sistema plantio direto, como é o caso dos ácidos orgânicos que disponibilizam oP presente nos fosfatos naturais reativos, da maior umidade superficial, proporcionando maior desenvolvimento radicular nessa região, bem como a incorporação de nutrientes por organismos de solo, em maior quantidade em solos cultivados com esse sistema (Silva et al., 1997).

Na safra 1998/1999, os índices de eficiência agronômica das adubações com superfosfato triplo e fosfato de Gafsa, em mistura ou na forma pura, aplicados a lanço, foram equivalentes (Tabela 3 ) e são semelhantes 
Tabela 3. Índices de eficiência agronômica avaliados no segundo cultivo.

\begin{tabular}{lcc}
\hline Fonte $^{(1)}$ & \multicolumn{2}{c}{ Soja $1998 / 1999$} \\
\cline { 2 - 3 } & Lanço & Sulco \\
\hline $100 \%$ ST & 100 & 96 \\
$67 \%$ ST+33\%FG & 78 & 49 \\
$33 \%$ ST+67\%FG & 82 & 17 \\
$100 \%$ FG & 94 & 3 \\
\hline
\end{tabular}

${ }^{(1)} \mathrm{ST}$ : superfosfato triplo; FG: fosfato de Gafsa.

aos obtidos por Casanova \& Solorzano (1994). Porém, quando aplicados no sulco de semeadura, a eficiência da mistura de fontes de $\mathrm{P}$ foi baixa. Davies (1984) também observou que a presença da fonte solúvel inibiu a dissolução do fosfato natural reativo e a produtividade foi proporcional à quantidade da fonte solúvel aplicada ao solo.

Apesar de ter havido alto teor de P no solo, quando o fosfato de Gafsa foi aplicado no sulco, observou-se que esse teor não atendeu às necessidades da cultura, resultando em menores produtividades, como pode ser verificado pelo índice de eficiência agronômica (Tabela 3).

\section{Conclusões}

1. As misturas de superfosfato triplo e fosfato de Gafsa, quando aplicadas no sulco de semeadura, apresentam menor eficiência agronômica, se comparadas ao superfosfato triplo puro.

2. O fosfato de Gafsa, quando aplicado a lanço, equivale ao superfosfato triplo.

3. O fosfato Gafsa não é eficiente para a cultura da soja, quando aplicado no sulco de semeadura.

\section{Referências}

BECK, M.A.; SANCHEZ, P.A. Soil phosphorus movement and budget after 13 years of fertilized cultivation in the Amazon basin. Plant and Soil, v.184, p.23-31, 1996.

BRAGA, N.R.; MASCARENHAS, H.A.A.; BULISANI, E.A.; RAIJ, B. van; FEITOSA, C.T.; HIROCE, R. Eficiência agronômica de nove fosfatos em quatro cultivos consecutivos de soja. Revista Brasileira de Ciência do Solo, v.15, p.315-319, 1991.

CASANOVA, E.F.; SOLORZANO, P.R. Sorghum and soybean response to natural and modified phosphate rock on acid soils in Venezuela. Communications in Soil Science and Plant Analysis, v.25, p.215-224, 1994.

CHIEN, S.H.; HAMMOND, L.L. A comparison of various laboratory methods for predicting the agronomic potencial of phosphate rocks for direct application. Soil Science Society of America Journal, v.42, p.935-939, 1978.

CHIEN, S.H.; MENON, R.G. Factors affecting the agronomic effectiveness of phosphate rock for direct application. Fertilizer Research, v.41, p.227-234, 1995.
CHOUDHARY, M.; PECK, T.R.; PAUL, L.E.; BAILEY, L.D. Longterm comparison of rock phosphate with superphosphate on crop yield in two cereal-legume rotations. Canadian Journal of Plant Science, v.74, p.303-310, 1994.

DAVIES, G.R. Comparison of water-insoluble phosphate fertilizer with superphosphate: a review. Journal of the Science of Food and Agriculture, v.35, p.265-271, 1984.

EMBRAPA. Centro Nacional de Pesquisa de Solos (Rio de Janeiro, RJ). Manual de métodos de análises de solo. 2.ed. Rio de Janeiro, 1997. 212p. (Embrapa-CNPS. Documentos, 1).

FOTYMA, M.; HAMMOND, L.; KESIK, K. Suitability of North Carolina natural phosphate to Polish agriculture. Fertilizer Research, v.43, p.83-86, 1996.

GILLESPIE, A.R.; POPE, P.E. Rhizosphere acidification increases phosphorus recovery of Black Locust - II: model predictions and measured recovery. Soil Science Society of America Journal, v.54, p.538-541, 1990.

GOEDERT, W.J.; LOBATO, E. Avaliação agronômica de fosfatos em solo de cerrado. Revista Brasileira de Ciência do Solo, v.8, p.97-103, 1984.

GOEDERT, W.J.; SOUSA, D.M.G. Uso eficiente de fertilizantes fosfatados. In: SEMINÁRIO FÓSFORO, CÁLCIO, MAGNÉSIO, ENXOFRE E MICRONUTRIENTES - SITUAÇÃO ATUAL E PERSPECTIVAS NAAGRICULTURA, 1, 1984, São Paulo. Anais. São Paulo: MANAH S/A, 1986. p.21-53.

KURIHARA, C.H.; MAEDA, S. Correção e adubação do solo. In: EMBRAPA. Centro de Pesquisa Agropecuária do Oeste (Dourados, MS). Soja: recomendações técnicas para Mato Grosso do Sul e Mato Grosso. Dourados: Embrapa-CPAO, 1996. 157p. (Circular Técnica, 3).

MALAVOLTA, E.; VITTI, G.C.; OLIVEIRA, S.A. Avaliação do estado nutricional das plantas: princípios e aplicações. Piracicaba: Potafos, 1997. 319p.

MARSCHNER, H. Root-induced changes in the avalability of micronutrients in the rhizosphere. In: WAISEL, Y.; ESHEL, A.; KAFKAFI, U. (Ed.). Plant roots: the hidden half. New York: Marcel Dekker, 1991. p.503-528.

MELO FILHO, G.A.; RICHETTI, A.; PARIZOTO, A.M. Aspectos socioeconômicos da cultura da soja. In: EMBRAPA. Centro de Pesquisa Agropecuária do Oeste (Dourados, MS). Soja: recomendações técnicas para Mato Grosso do Sul e Mato Grosso. Dourados: Embrapa-CPAO, 1996. p.9-33. (Circular Técnica, 3).

NOVAIS, R.F.; SMYTH, R.J. Fósforo em solo e planta em condições tropicais. Viçosa: UFV, 1999. 399p.

RAIJ, B. van; QUAGGIO, J.A.; SILVA, N.M. da. Extraction of phosphorus, potassium, calcium and magnesium from soils by an ion-exchange resin procedure. Communications in Soil Science and Plant Analysis, v.17, p.547-566, 1986.

RAJAN, S.S.S.; WATKINSON, J.H.; SINCLAIR, A.G. Phosphate rocks for direct application to soils. Advances in Agronomy, v.57, p.77-159, 1996.

SILVA, M.T.B. da;ANTONIOLLI,Z.I.; PETRERE, C.; BIANCHI, M.A.; GIRACCA, E.M.N. Influência de larvas de Diloboderus abderus (Sturm) na densidade de organismos e características químicas de solo. Revista Brasileira de Ciência do Solo, v.21, p.347-351, 1997.

Recebido em 2 de julho de 2003 e aprovado em 23 de dezembro de 2003 